\section{Optimum time for neostigmine reversal of atracurium-induced neuromuscular blockade}

Hans Kirkegaard-Nielsen MD,

Hans Søren Helbo-Hansen MD, Peter Lindholm MD, Inge Krogh Severinsen MD, Henrik Stougaard Pedersen MD, Erik Weber Jensen MSc
Purpose: The aim of the study was to determine the optimum time for administration of neostigmine during recovery from atracurium-induced neuromuscular blockade.

Methods: The study comprised 103 patients anaesthetised with midazolam, fentanyl, thiopentone, halothane, and nitrous oxide. Relaxation was induced with atracurium $0.5 \mathrm{mg} \cdot \mathrm{kg}^{-1}$ and maintained with supplements of $0.15 \mathrm{mg} \cdot \mathrm{kg}^{-1}$. The ulnar nerve was stimulated with train-of-four (TOF) and double burst stimulation (DBS). Evoked MMG responses were recorded. Patients were randomized to spontaneous recovery $(n=20)$ or to assisted recovery by neostigmine $(0.07$ $\left.\mathrm{mg} \cdot \mathrm{kg}^{-1}\right)$ at varying intervals $(6-50 \mathrm{~min})$ from the last atracurium dose $(n=83)$.

Results: The reversal time (time from administration of neostigmine to TOF ratio 0.7$)$ was always $<13 \mathrm{~min}$, when $T_{1}$ (first twitch in TOF) was detectable or when $D_{1}$ (first twitch in $D B S$ ) was $>5 \%$. Total assisted recovery time (time from last supplemental atracurium dose to TOF ratio 0.7$)$ increased with increasing $T_{1}$ and $D_{1}$ twitch heights $(P<0.05)$. The curve fitted to the scattergram with total assisted recovery time vs time from last atracurium supplement to neostigmine administration decreased to reach a minimum after which it increased to approach the line of identity. The minimum of the curve (total assisted recovery time $30.7 \mathrm{~min}$ ) was reached when neostigmine was given 18.6 min after last atracurium supplement. At this time the $T$, and $D_{1}$ twitch height averaged 4 and

\section{Key words}

ANTAGONISTS: neostigmine;

MONITORING: neuromuscular transmission, train-of-four, double burst stimulation;

NEUROMUSCULAR RELAXANTS: atracurium.

From the Department of Anaesthesia and Intensive Care, Odense University Hospital, DK-5000 Odense C, Denmark.

Address correspondence to: Dr. H. Kirkegaard-Nielsen, Department of Anaesthesia and Intensive Care, Odense University Hospital, DK-5000 Odense C, Denmark.

Fax +45 66132854 .

Accepted for publication 26th April, 1996.
$8 \%$ respectively. If prolongation of the minimum total recovery time of $2.5 \%$ is accepted, neostigmine can be given at $T_{I}$ and $D_{1}$ twitch height values of 0 to $8 \%$ and 4 to $15 \%$, respectively.

Conclusion: The optimum time for neostigmine administration, taking both the reversal time and total recovery time into consideration, is when $0<T_{1}<8 \%$ or when $5<D_{1}<15 \%$. Giving neostigmine at more profound degrees of blockade prolongs reversal time, while giving neostigmine later in the recovery phase prolongs total recovery time.

Objectif: Déterminer le moment idéal pour l'administration de la néostigmine pendant la phase de récupération du bloc neuromusculaire induit par l'atracurium.

Méthodes: Cette étude évaluait 103 patients anesthésiés au midazolam, fentanyl, thiopentone, halothane et protoxyde d'azote. La relaxation était induite par l'atracurium $(0,5$ $\mathrm{mg} \cdot \mathrm{kg}^{-1}$ ) et entretenue avec des suppléments de $0,15 \mathrm{mg} \cdot \mathrm{kg}^{-1}$. Le nerf cubital était stimulé avec le train-de-quatre (TOF) et la suppression du double burst (DBS). Les réponses $M M G$ évoquées étaient enregistrées. Les patients étaient répartis au hasard entre récupération spontanée $(n=20)$ et assistée par la néostigmine $\left(0,07 \mathrm{mg} \cdot \mathrm{kg}^{-1}\right)$ à intervalles variés $(6-50 \mathrm{~min})$ après la dernière doses d'atracurium $(n=83)$.

Résultats: Le temps de neutralisation (l'intervalle entre l'administration de la néostigmine et le retour du rapport TOF 0,7 ) était toujours <13 min, au moment où $T_{1}$ (premier twitch du TOF) était détecté ou quand $D_{1}$ (premier twitch du DBS) était $>5 \%$. Le temps de la récupération assistée (l'intervalle entre la dernière dose supplémentaire d'atracurium et le rapport TOF $=0,7)$ augmentait simultanément avec l'ampleur de $T_{1}$ et $D_{l}(P<0,05)$. La courbe du diagramme de dispersion ajustée à la récupération totale assistée vs l'intervalle entre le dernier supplément d'atracurium et l'administration de la néostigmine diminuait pour atteindre un minimum après quoi elle augmentait pour s'approcher de la ligne d'identité. Le creux de la courbe (temps total de récupération assistée 30,7 min) était atteint quand la néostigmine était administrée 18,6 min après le dernier supplément d'atracurium. À ce moment, la hauteur des twitch $T_{1}$ et $D_{1}$ était respectivement de 4 et $8 \%$. 
Conclusion: En considérant à la fois le temps de neutralisation et le temps total de récupération, le moment idéal pour administrer la néostigmine se situe quand $0<T_{1}<0,8 \%$ ou quand $5<D_{1}<15 \%$. L'administration de la néostigmine à des niveaux de bloc plus profonds prolonge le temps de neutralisation; l'administration plus tardive de néostigmine pendant la période de récupération prolonge le temps de récupération totale.

The time from administration of neostigmine during recovery from non-depolarizing neuromuscular blockade until the train-of-four (TOF) ratio recovers to 0.7 (reversal time) depends upon the degree of blockade at the time of reversal. ${ }^{1-5}$ Moderate and shallow degrees of atracurium-induced blockade are promptly and completely reversed by neostigmine. ${ }^{2,6-9}$ Reversal from profound degrees of atracurium induced blockade (no response to TOF stimulation) has also been studied. ${ }^{4,10,11}$ Neostigmine administered during profound blockade reduces the time from administration of the last supplementary dose of atracurium until the TOF ratio has recovered to 0.7 (total recovery time), but the reversal time is long and very variable and no time is saved compared with that after reversal at $10 \%$ recovery of the first twitch in TOF $\left(T_{1}\right)$. Therefore, reversal of profound blockade has no clinical advantage.

The above studies dealt only with reversal from isolated narrow ranges of different degrees of neuromuscular blockade and, furthermore, focused mainly on the reversal time. Thus, the borderline between prompt and complete reversal, and slow and unpredictable reversal is uncertain. The aim of the present study was to determine the optimum time for administration of neostigmine during recovery from atracurium-induced neuromuscular blockade.

\section{Methods}

\section{Patients}

We studied 103 ASA physical status I-II adult patients (18 to $60 \mathrm{yr}$ ) undergoing elective gynaecological surgery. Patients with a body weight $>80 \mathrm{~kg}$, suffering from neuromuscular disease, or under treatment with drugs, which might interfere with neuromuscular transmission, were excluded. The protocol was approved by the local Ethics Committee, and written informed consent was obtained.

\section{Anaesthesia}

The patients received premedication with dixyrazine (a phenothiazine derivative) $50 \mathrm{mg}$ po the night before surgery. Anaesthesia was induced with midazolam 0.04 $\mathrm{mg} \cdot \mathrm{kg}^{-1}$ and fentanyl $3 \mu \mathrm{g} \cdot \mathrm{kg}^{-1}$ followed by thiopentone $5 \mathrm{mg} \cdot \mathrm{kg}^{-1}$ and maintained with halothane $0.5 \%$ end-tidal concentration (Normac ${ }^{\circledR}$, Datex, Finland), 65 to $70 \%$ nitrous oxide in oxygen, and supplementary doses of $100 \mu \mathrm{g}$ fentanyl , $50 \mathrm{mg}$ thiopentone or $1 \mathrm{mg}$ midazolam as required, according to heart rate and blood pressure. Ventilation was adjusted to maintain the end-tidal carbon dioxide partial pressure between 4.9-5.7 $\mathrm{kPa}$ (37-43 mmHg) (Normocap ${ }^{\circledR}$, Datex, Finland). Temperatures were monitored continuously in the nasopharynx or oesophagus and at the hand used for the neuromuscular monitoring. (TR9 ${ }^{\circledR}$, Ellab, Denmark). The patient was covered with warm blankets, the saline used for infusion was warmed, and the temperature in the operation theatre was kept $>20^{\circ} \mathrm{C}$.

\section{Neuromuscular blockade}

Neuromuscular blockade was induced with a bolus dose $0.5 \mathrm{mg} \cdot \mathrm{kg}^{-1}$ of atracurium and maintained with supplementary doses of $0.15 \mathrm{mg} \cdot \mathrm{kg}^{-1}$ atracurium whenever the height of the first twitch of the TOF $\left(T_{1}\right)$ recovered to $15 \%$ of the control twitch height ( $\mathrm{T}_{1}$ control).

The patients were allocated randomly either to spontaneous recovery $(n=20)$ or to assisted recovery by $0.07 \mathrm{mg} \cdot \mathrm{kg}^{-1}$ neostigmine (equivalent to $5 \mathrm{mg} \cdot \mathrm{kg}^{-1}$ ) and $0.028 \mathrm{mg} \cdot \mathrm{kg}^{-1}$ atropine (equivalent to $2 \mathrm{mg} \cdot 70$ $\left.\mathrm{kg}^{-1}\right)(n=83)$. The patients allocated to neostigmine assisted recovery were further allocated randomly to receive neostigmine at varying time intervals (6-50 $\mathrm{min}$ ) from the last supplementary dose of atracurium.

\section{Neuromuscular monitoring}

The ulnar nerve was stimulated supramaximally at the wrist using 0.2 or $0.3 \mathrm{msec}$ square wave currents (Myotest DBS $^{\circledR}$, Biometer, Denmark). Currents of 0.3 msec were used if currents of $0.2 \mathrm{msec}$ did not secure supramaximal stimulation. Initially single twitch $(1 \mathrm{~Hz})$ stimulation was used. When the response after approximately 10 min was stable, the stimulation mode was switched to train-of-four stimulation (TOF: four stimuli at $2 \mathrm{~Hz}$ delivered every $12 \mathrm{sec}$ ), and the height of the first twitch in TOF $\left(T_{1}\right)$ recorded as the control twitch height $\left(T_{1}\right.$ control). When response to TOF disappeared after administration of atracurium the stimulation mode was switched to double burst stimulation (DBS: burst of three stimuli at $50 \mathrm{~Hz}$ followed $0.75 \mathrm{sec}$ later by an identical burst) delivered every $20 \mathrm{sec}$. Intubation was performed, when response to DBS disappeared.

Patients allowed to recover spontaneously received repeated sequences of four DBS and six TOF stimulation patterns from administration of the last supplementary dose of atracurium. Only responses to the fourth DBS stimulation and to the sixth TOF stimulation in 
the DBS and TOF sequences, respectively, were recorded.

Patients allocated to neostigmine assisted recovery received DBS stimulation from administration of the last supplementary dose of atracurium. The stimulation mode was switched to TOF at reappearance of response to DBS stimulation. Four DBS stimulations were later interposed $80 \mathrm{sec}$ before the appointed time of administration of neostigmine (time of reversal). Only responses to the fourth DBS stimulation were recorded. The TOF response at the time of reversal was obtained by linear extrapolation of the TOF responses preceding the four DBS stimulations.

Evoked contractions of the adductor pollicis muscle were measured using a force-displacement transducer with a pre-load of $300 \mathrm{~g}$ (Myograph 2000, Biometer, Denmark). The $T_{1}$ and the twitch heights of the first and second twitch in DBS $\left(D_{1}\right.$ and $D_{2}$, respectively) were measured as $\%$ of $T_{1}$ control. The twitch heights were recorded from the digital display on the Myograph. Due to filtering in the analogue-to-digital converter in the Myograph, twitch heights $<4 \%$ did not consistently appear on the digital display. Therefore, twitch heights $<4 \%$ identified on the graph but not appearing on the digital display were given the value $2 \%$. Neuromuscular monitoring continued until the TOF ratio recovered to $>0.7$.

\section{Definitions \\ Reversal time: Time from administration of neostigmine until the TOF ratio recovered to 0.7 . \\ Pre-reversal time: Time from administration of the last supplementary dose of atracurium until administration of neostigmine. \\ Total spontaneous recovery time: Time from adminis- tration of the last supplementary dose of atracurium until the TOF ratio recovered to 0.7 in patients allowed to recover spontaneously. \\ Total assisted recovery time. Time from administration of the last supplementary dose of atracurium until the TOF ratio recovered to 0.7 in the patients receiving neostigmine (i.e., pre-reversal time plus reversal time).}

\section{Statistics}

Students $t$ test for unpaired data, least square regression analyses and ANOVA were used, $P<0.05$ was considered as statistically significant.

\section{Results}

The mean \pm SD (range) age and body weight of the patients were $43 \pm 7(24-60)$ yr and $64.3 \pm 7.4(48-79)$ $\mathrm{kg}$, respectively.

The time from administration of the initial dose of

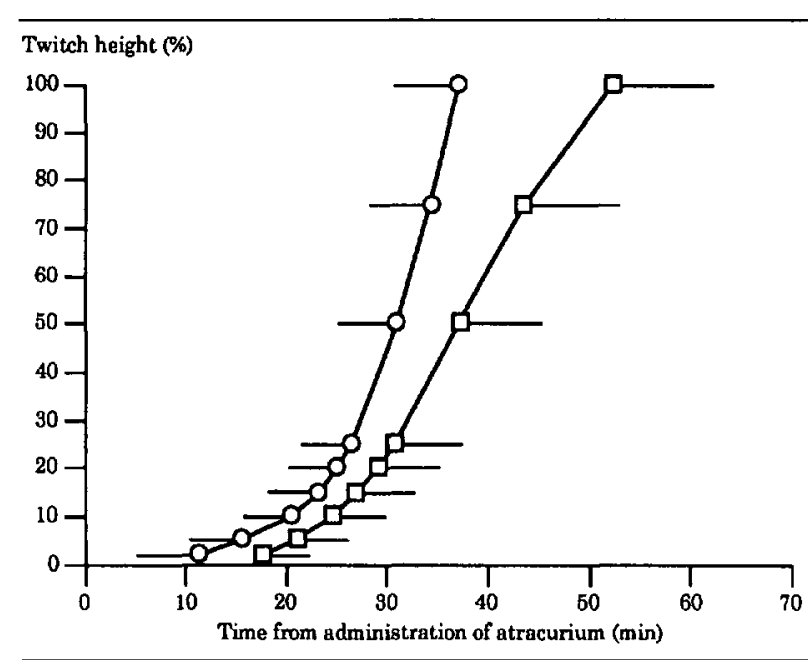

FIGURE 1. Time course of $D_{1}$ and $T_{1}$ twitch heights (\%) vs time from administration of the last dose of atracurium in patients allowed to recover spontaneously. Values are mean with standard deviations indicated by horizontal bars. Open circles represent $D_{1}$ in percent of $T_{1}$ control, open boxes represent $T_{1}$ in percent of $T_{1}$ control.

atracurium until the TOF ratio recovered to 0.7 was 108 \pm 25.7 (58.2-200.7) $\mathrm{min}$. The number of supplementary doses of atracurium ranged from one to four.

The total spontaneous recovery time was $57.1 \pm 9.2$ (42.8-76.0) (mean $\pm \mathrm{SD}$ (range)) min.

The recovery courses of $D_{1}$ and $T_{1}$ in the group of patients allowed to recover spontaneously are depicted in Figure 1. The times from administration of the last supplemental dose of atracurium until reappearance of $D_{1}$ and $T_{1}$ and until $D_{1}$ and $T_{1}$ recovered to $5,10,15,20$, $25,50,75$ and $100 \%$, respectively, are shown. The times from reappearance of $D_{1}$ and $T_{1}$ and from the times when $D_{1}$ and $T_{1}$ had recovered to $5,10,15,20,25,50$, 75 and $100 \%$ until the TOF ratio recovered to 0.7 are shown in Tables I and II.

The relationships between $T_{1}$ at the time of reversal and total recovery time, and between $T_{1}$ and the reversal time are depicted in Figure 2. When $T_{1}$ was $>$ zero, the reversal time was $<12.7 \mathrm{~min}$. Total recovery time correlated with $\mathrm{T}_{1}(P<0.0001)$.

The relationships between $D_{1}$ at the time of reversal and total recovery time, and between $D_{1}$ and the reversal time are depicted in Figure 3. When $D_{1}$ was $\leq 5 \%$, reversal time was $22.4 \pm 6.3(12.6-41) \mathrm{min}$, while the total recovery time was $33.8 \pm 5.4(22.6-48)$ min. When $D_{1}$ was $>5 \%$, reversal time was $<13 \mathrm{~min}$. Total recovery time correlated with $\mathrm{D}_{1}(P<0.0001)$.

The relationship between time from atracurium supplementation to neostigmine administration $(x)$ and total assisted recovery time $(\mathrm{y})$ is depicted in Figure 4. Correlation analysis revealed a negative correlation 
TABLE I Elapsed time from reappearance of $D_{1}$ and from when $D_{1}$ had recovered to $5,10,15,20,25,50,75$ and $100 \%$, respectively, until the TOF ratio reached 0.7 in patients allowed to recover spontaneously. Values are mean $\pm \mathrm{SD}$ (range).

\begin{tabular}{lll}
\hline$D_{1}(\%)$ & \multicolumn{2}{l}{ Elapsed time $(\mathrm{min})$ until TOF ratio 0.7} \\
\hline Reappearance & $46.1 \pm 6.8$ & $(37.1-59.0)$ \\
5 & $41.8 \pm 6.8$ & $(33.8-54.8)$ \\
10 & $38.4 \pm 5.6$ & $(31.8-48.3)$ \\
15 & $35.7 \pm 5.0$ & $(29.8-44.5)$ \\
20 & $33.8 \pm 4$. & $(27.1-42.3)$ \\
25 & $32.4 \pm 4.6$ & $(25.5-40.6)$ \\
50 & $27.2 \pm 4.0$ & $(21.5-35.0)$ \\
75 & $23.7 \pm 3.7$ & $(18.6-31.6)$ \\
100 & $21.0 \pm 3.6$ & $(16.0-28.8)$ \\
\hline
\end{tabular}

Table II Elapsed time from reappearance of $T_{1}$ and from when $T_{1}$ had recovered to $5,10,15,20,25,50,75$ and $100 \%$, respectively, until the TOF ratio reached 0.7 in patients allowed to recover spontaneously. Values are mean $\pm \mathrm{SD}$ (range).

\begin{tabular}{lll}
\hline$T_{1}(\%)$ & \multicolumn{2}{c}{ Elapsed time } \\
\hline Reappearance & $39.0 \pm 6.7$ & $(30.8-53.7)$ \\
5 & $35.8 \pm 5.6$ & $(28.1-48.6)$ \\
10 & $32.3 \pm 4.8$ & $(25.1-42.1)$ \\
15 & $30.0 \pm 4.1$ & $(23.7-38.2)$ \\
20 & $27.8 \pm 4.0$ & $(21.8-36.2)$ \\
25 & $26.0 \pm 3.8$ & $(20.5-34.0)$ \\
50 & $19.0 \pm 4.2$ & $(8.2-26.1)$ \\
75 & $13.2 \pm 3.9$ & $(7.2-23.2)$ \\
100 & $4.8 \pm 4.0$ & $(-0.7-10.1)$ \\
\hline
\end{tabular}

between pre-reversal time and total assisted recovery time in the interval 6 to 17 min after atracurium supplementation $(P<0.05)$ and a positive correlation between pre-reversal time and total recovery time in the interval 19 to $50 \mathrm{~min}(P<0.0001)$. Furthermore, the $\mathrm{x}-\mathrm{y}$ relationship has a minimum. When two linear regressions were fitted to the data, the least mean square (LMS) was 1720.2. When one linear regression and one exponentially fit was chosen, LMS was 1644.4 , which was less than LMS for the double linear function $(P<0.05)$. The complete dependence was modelled by the function $y=$ $-0.32 x+36$ when $x \leq 15 \mathrm{~min}$, and $\mathrm{y}=57 . \exp (-\mathrm{x} / 12)+$ $x$ when $x>15 \mathrm{~min}$. The coefficients were calculated to give the best fit in a LMS sense. The minimum of the curve was at $y=30.7 \mathrm{~min}$ for $\mathrm{x}=18.6 \mathrm{~min}$. In other words, the shortest total assisted recovery time of 30.7 min was obtained when neostigmine was administered $18.6 \mathrm{~min}$ after the last supplemental dose of atracurium. If the data were grouped by pre-reversal time intervals: Group I pre- reversal time 10 to $16 \mathrm{~min}$, Group II pre-reversal time 16 to $20 \mathrm{~min}$, and Group III pre-reversal time 20 to $31 \mathrm{~min}$, it was found that the mean total

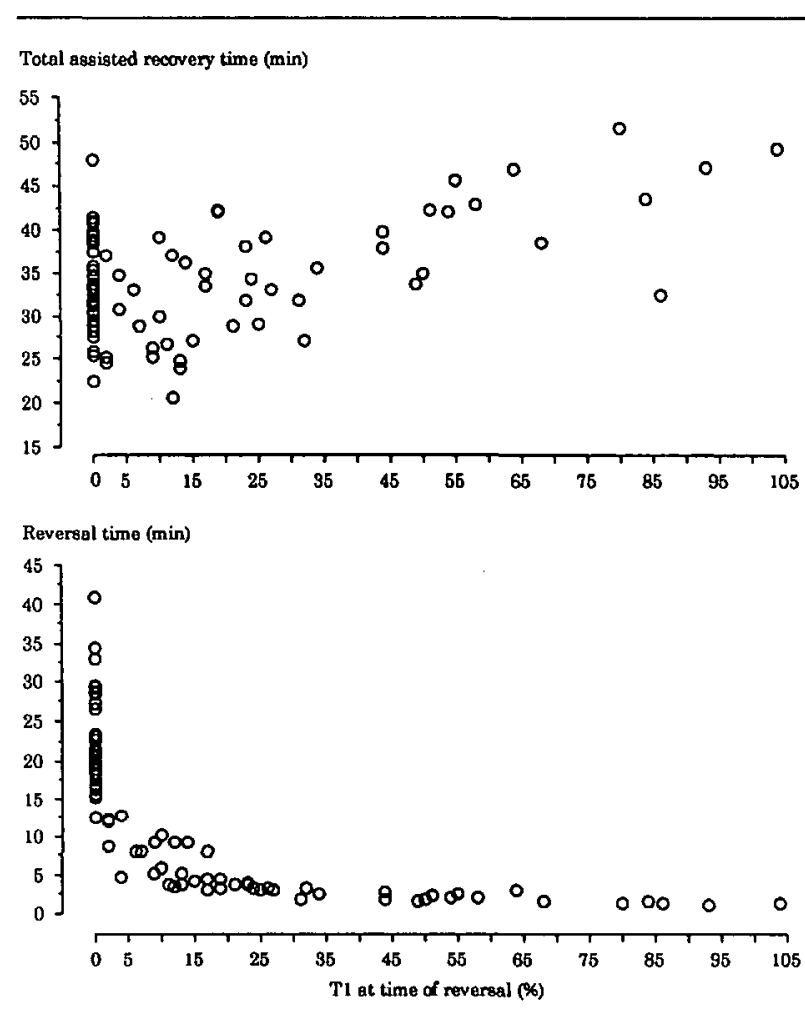

FIGURE 2 The relationship between $\mathrm{T}_{1}$ at the time of reversal (\%) and the total assisted recovery time ( $\mathrm{min}$ ) and between $\mathrm{T}_{1}$ and the reversal time (min).

recovery time in Group II was smaller than the mean total recovery time in Group I and III respectively $(P=$ 0.039 ). This indicates that the minimum of the curve is in the pre-reversal time interval 16 to $20 \mathrm{~min}$, which is consistent with the finding from the curve, where the analytic minimum can be calculated to $18.6 \mathrm{~min}$.

The shortest total assisted recovery time was shorter than the total spontaneous recovery time $(P<0.05)$. The time gained by assisting recovery averaged $26.3 \mathrm{~min}$.

The temperature at the thenar eminence was $>32.0^{\circ} \mathrm{C}$ and the central temperature was $>36.0^{\circ} \mathrm{C}$ at all times.

\section{Discussion}

The present study indicates that the optimal time for administration of neostigmine during recovery from atracurium induced blockade is when $0<\mathrm{T}_{1}<8 \%$ or when $5<D_{1}<15 \%$. The reversal time increases when neostigmine is administered at more profound degrees of blockade, and the total recovery time increases when neostigmine is given at more shallow degrees of blockade.

End-tidal halothane concentration was kept constant 


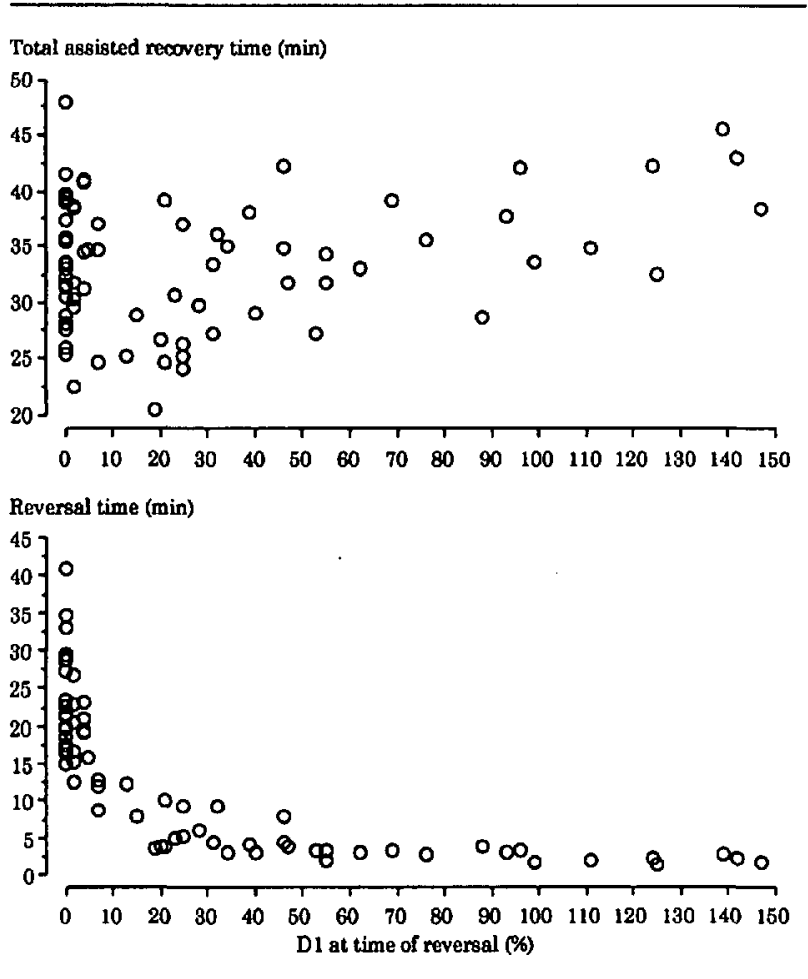

FIGURE 3 The relationship between $D_{1}$ at the time of reversal (\%) and the total assisted recovery time ( $\mathrm{min}$ ) and between $\mathrm{D}_{1}$ and the reversal time ( $\mathrm{min})$.

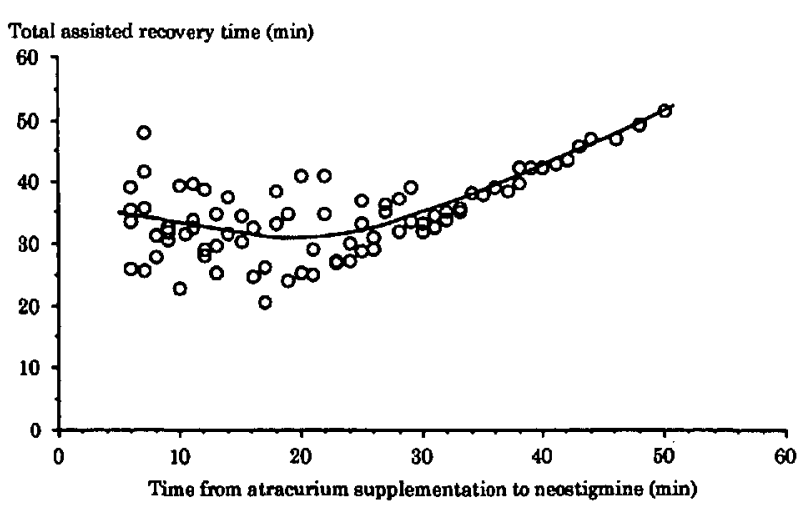

FIGURE 4 The relationship between pre-reversal time (time from atracurium supplementation to neostigmine) and the total assisted recovery time. The relationship was modelled by the functions $y=$ $-0.32 x+36$ for $x \leq 15$ and $y=57 e^{(-x / 12)}+x$ for $x>15$

until the TOF ratio had recovered to 0.7 . This eliminated sudden movement, which might have interfered with the neuromuscular monitoring. The technique may differ from clinical practice, where the inhalation of halothane often is discontinued at the time of antagonism. As halothane intensifies the effect of neuromuscular relaxants and retards antagonism, ${ }^{12,13}$ the optimum time for administration of neostigmine, may occur at deeper levels of blockade, if halothane is discontinued earlier, or if it is not used at all.

Both TOF and DBS modes were evaluated as markers, because a previous study indicated that the optimum time for antagonism of vecuronium was at $0-15 \%$ recovery of $T_{1} \cdot{ }^{14}$ Double burst stimulation is capable of monitoring more intense degrees of blockade than TOF $^{15}$ and will, therefore, provide a more differentiated measure of the degree of blockade, when $T_{1}$ is close to $0 \%$. Both $\mathrm{T}_{1}$ and $\mathrm{D}_{1}$ were measured in $\%$ of $\mathrm{T}_{1}$ control. One could argue that $\mathrm{D}_{1}$ should be measured as \% of $\mathrm{D}_{1}$ control but this would abolish the advantage from the more forceful contractions produced by double burst stimulation. Furthermore it would be bothersome to operate with two different control levels. In the clinical setting, when mechanomyography is used for neuromuscular monitoring, stimulation will be with TOF most of the time and DBS will only be used during deep degrees of blockade.

The design with only one arm used for neuromuscular monitoring posed the problem that TOF and DBS stimulations could not be delivered simultaneously. Furthermore, when switching from TOF to DBS or vice versa it took time before the responses to the succeeding stimulation mode had stabilised. ${ }^{16}$ These problems were overcome (1) by interposing four DBS stimulations immediately before antagonism, (2) by using the response to the fourth stimulation (representing the stable response coinciding with antagonism), and (3) by linearly extrapolating the responses of the preceding TOF stimulation to the time of antagonism.

Neostigmine was chosen in favour of edrophonium, as neostigmine is more effective than edrophonium in reversal of profound degrees of block. ${ }^{2,3,17,18}$ The dose of neostigmine of $70 \mu \mathrm{g} \cdot \mathrm{kg}^{-1}$ was chosen as we intended to study the maximal antagonising effect. The effect of neostigmine increases with increasing doses to a ceiling, beyond which further amounts of neostigmine produce no additional antagonism. ${ }^{19}$ There is, however, no general agreement of the size of the ceiling in humans. Some studies have demonstrated a greater effect of $70-80 \mu \mathrm{g} \cdot \mathrm{kg}^{-1}$ neostigmine than $40 \mu \mathrm{g} \cdot \mathrm{kg}^{-1}$ neostigmine at reversal from $5-10 \% \mathrm{~T}_{1}$ recovery ${ }^{5,9,20}$ while others have demonstrated that the difference between the two doses was negligible. ${ }^{21,22}$ A TOF ratio of $0.70-0.75$ is normally considered to reflect adequate recovery from neuromuscular blockade. ${ }^{23}$ Thus the neuromuscular monitoring continued until the TOF ratio recovered to $>0.70$. However, it has been reported that some muscle weakness may be present even at a TOF ratio of $0.70 . .^{24}$

In order to study reversal from the entire range of dif- 
ferent degrees of neuromuscular blockade, we randomised the patients to reversal at different times from the last supplementary dose of atracurium. As we assumed the reversal time to be more variable during profound degrees of blockade, more patients were randomised to reversal at short time intervals (6-10 min) from the last supplementary dose of atracurium than to reversal from more shallow degrees of block (20-40 min).

The reversal time is a function of two processes: (1) spontaneous recovery rate of atracurium and (2) enhanced recovery promoted pharmacologically with neostigmine. The time to peak effect of neostigmine is $8.0 \pm 1.9$ min (mean $\pm \mathrm{SD})^{20}$ implying that the maximal effect of neostigmine is achieved within $13 \mathrm{~min}$ (mean + $2.576 \mathrm{SD}$ ) in approximately $99 \%$ of the patients. Further recovery taking place $>13 \mathrm{~min}$ after antagonism is, therefore, exclusively dependent on the ongoing spontaneous recovery. Based on these data it does not seem reasonable to accept reversal times $>13 \mathrm{~min}$.

The results of the present study showed that the reversal time was $<13 \mathrm{~min}$ in all patients when response to $T_{1}$ had reappeared or when $D_{1}$ had recovered to $>5 \%$. Furthermore, reversal time was $>12 \mathrm{~min}$ in all patients, when the response to TOF was abolished, or when $D_{1}$ $\leq 5 \%$. Consequently, reappearance of the response to TOF or recovery of $D_{1}$ to $6 \%$ may serve as markers for the earliest time for antagonism. A previous study has shown that $D_{1}$ reappears before $T_{1}$ during recovery. ${ }^{25}$ Therefore, $D_{1}$ may be preferable to $T_{1}$ as a predictor as it gives an earlier warning that the optimum time for antagonism is near.

In order to define the optimum point for antagonism, one also has to take into consideration the total recovery time. The total assisted recovery time was found to increase with increasing $T_{1}$ and $D_{1}$ twitch heights implying a waste of time if neostigmine is given too late. To get a more differentiated picture of the relationship between the degree of block and total recovery time, we also determined the relationship between the total assisted recovery time and the pre-reversal time. This relationship showed that total recovery time initially decreased, reached a minimum, and finally increased again approaching the line of identity. Neostigmine given shortly after atracurium supplementation cannot reverse the blockade totally, and when a TOF ratio of 0.7 finally is reached, neostigmine has lost some of its effect because of the ongoing elimination processes. This is the explanation for the longer total recovery time when neostigmine is given very early in the recovery phase. The curve showed that the minimum total assisted recovery time averaged $30.7 \mathrm{~min}$, when neostigmine was administered $18.6 \mathrm{~min}$ after the last supplemental dose of atracurium. This analytic curve minimum is consistent with the finding that the mean total assisted recovery time in the pre-reversal time interval 16 to 20 $\mathrm{min}$ is smaller than the total assisted recovery time in the pre-reversal interval 10 to $16 \mathrm{~min}$ and 20 to $31 \mathrm{~min}$ respectively $(P<0.05)$. The total assisted recovery time is shorter than the total spontaneous recovery time of $57.0 \mathrm{~min}(P<0.05)$. The maximum time gained by giving neostigmine averaged $26.3 \mathrm{~min}$ (57.0 minus 30.7 min). In Figure 1 we can see that 18.6 min after the last supplemental dose of atracurium corresponds to a $\mathrm{T}_{1}$ of approximately $4 \%$ and a $D_{1}$ of approximately $8 \%$. The fitted curve is flat around its minimum. It is therefore reasonable to accept some variation in the minimum total assisted recovery time. A $2.5 \%$ prolongation of the minimum total assisted recovery time implies a pre-reversal time interval from 14.2 to $23.3 \mathrm{~min}$. The pre-reversal time is obtained by solving the equations describing the curve in Figure 4 for a y value of 31.47 min. From Figure 1 it can be seen that this pre-reversal time interval corresponds to a $T_{1}$ interval of 0 to $8 \%$ and a $\mathrm{D}_{1}$ interval of 4 to $15 \%$.

The results obtained may be influenced by the anaesthetic technique, the blocking agent and the neostigmine dose. Therefore, one should be cautious about generalising from the results of the present study.

Taking both the reversal time and total recovery time into consideration we conclude that the optimal time for neostigmine administration is when $0<\mathrm{T}_{1}<8 \%$ or when $5<\mathrm{D}_{1}<15 \%$. Giving neostigmine at more profound degrees of blockade will prolong reversal time and this is clinically undesirable. Giving neostigmine at non shallow degrees of blockade may prolong total recovery time. The $D_{1}$ appears superior to $T_{1}$ as a marker as $D_{1}$ gives an earlier warning of the optimum time for antagonism.

\section{References}

1 Hennart D, d'Hollander A, Plasman C, De Jonckheere M. Importance of the level of paralysis recovery for a rapid antagonism of atracurium neuromuscular blockade with moderate doses of edrophonium. Anesthesiology 1986; 64: 384-7.

2 Rupp SM, McChristian JW, Miller RD, Taboada JA, Cronnelly $R$. Neostigmine and edrophonium antagonism of varying intensity neuromuscular blockade induced by atracurium, pancuronium, or vecuronium. Anesthesiology 1986; 64: 711-7.

3 Donati F, Lahoud J, McCready D, Bevan DR. Neostigmine, pyridostigmine and edrophonium as antagonists of deep pancuronium blockade. Can J Anaesth 1987; 34: 589-93.

4 Engbaek J, Østergaard D, Skovgaard LT, Viby-Mogensen 
$J$. Reversal of intense neuromuscular blockade following infusion of atracurium. Anesthesiology 1990; 72: 803-6.

5 Beemer GH, Bjorksten AR, Dawson PJ, Dawson RJ, Heenan PJ, Robertson BA. Determinants of the reversal time of competitive neuromuscular block by anticholinesterases. Br J Anaesth 1991; 66: 469-75.

6 Payne JP, Hughes $R$. Evaluation of atracurium in anaesthetized man. Br J Anaesth 1981; 53: 45-54.

7 Basta SJ, Ali HH, Savarese JJ, et al. Clinical pharmacology of atracurium besylate (BW 33A): a new non-depolarizing muscle relaxant. Anesth Analg 1982; 61: 723-9.

8 Astley BA, Hughes $R$, Payne JP. Antagonism of atracurium-induced neuromuscular blockade by neostigmine or edrophonium. Br J Anaesth 1986; 58: 1290-5.

9 Harper NJN, Wallace M, Hall IA. Optimum dose of neostigmine at two levels of atracurium-induced neuromuscular block. Br J Anaesth 1994; 72: 82-5.

10 Caldwell JE, Robertson EN, Baird WLM. Antagonism of profound neuromuscular blockade induced by vecuronium or atracurium. Br J Anaesth 1986; 58: 1285-9.

11 Magorian TT, Lynam DP, Caldwell JE, Miller RD. Can early administration of neostigmine, in single or repeated doses, alter the course of neuromuscular recovery from a vecuronium-induced neuromuscular blockade? Anesthesiology 1990; 73: 410-4.

12 Delisle $S$, Bevan DR. Impared neostigmine antagonism of pancuronium during enflurane anaesthesia in man. $\mathrm{Br} \mathrm{J}$ Anaesth 1982; 54: 441-5.

13 Baurain MJ, d'Hollander AA, Melot C, Dernovoi BS, Barvais $L$. Effects of residual concentrations of isoflurane on the reversal of vecuronium-induced neuromuscular blockade. Anesthesiology 1991; 74: 474-8.

14 Kirkegaard-Nielsen H, May O. Prediction of reversal time and optimal time of neostigmine administration in atracurium blockade. (German) Anaesthesist 1994; 43: 528-33.

15 Kirkegaard-Nielsen H, May $O$. Double burst stimulation for monitoring profound neuromuscular blockade: a comparison with posttetanic count and train of four. Acta Anaesthesiol Belg 1992; 43: 253-7.

16 Kirkegaard-Nielsen H, Helbo-Hansen HS, Lindholm P, Krogh Severinsen I, Bülow K, Jensen EW. Stabilization of the neuromuscular response when switching between different modes of nerve stimulation at surgical degrees of neuromuscular blockade. J Clin Monit 1995; 11: 317-23.

17 Donati $F$, Smith $C E$, Bevan DR. Dose-response relationships for edrophonium and neostigmine as antagonists of moderate and profound atracurium blockade. Anesth Analg 1989; 68: 13-9.

18 Caldwell JE, Robertson EN, Baird WLM. Antagonism of vecuronium and atracurium: comparison of neostigmine and edrophonium administered at $5 \%$ twitch height recovery. Br J Anaesth 1987; 59: 478-81.
19 Bartkowski $R R$. Incomplete reversal of pancuronium neuromuscular blockade by neostigmine, pyridostigmine, and edrophonium. Anesth Analg 1987; 66: 594-8.

20 Kirkegaard-Nielsen H, Helbo-Hansen HS, Lindholm P, Severinsen IK, Bülow $K$. Time to peak effect of neostigmine at antagonism of atracurium- or vecuronium-induced neuromuscular block. J Clin Anesth 1995; 7: 635-9.

21 Fox MA, Keens SJ, Utting JE. Neostigmine in the antagonism of the action of atracurium. $\mathrm{Br} J$ Anaesth $1987 ; 59$ : 468-72.

22 Jones $J E$, Hunter $J M$, Utting $J E$. Use of neostigmine in the antagonism of residual neuromuscular blockade produced by vecuronium. Br J Anaesth 1987; 59: 1454-8.

23 Ali HH, Wilson RS, Savarese JJ, Kitz, RJ. The effect of tubocurarine on indirectly elicited train-of-four muscle response and respiratory measurements in humans. $\mathrm{Br} \mathrm{J}$ Anaesth 1975; 47: 570-4.

24 Brand JB, Cullen DJ, Wilson NE, Ali HH. Spontaneous recovery from nondepolarizing neuromuscular blockade: correlation between clinical and evoked responses. Anesth Analg 1977; 56: 55-8.

25 Kirkegaard-Nielsen H, Helbo-Hansen HS, Severinsen IK, Lindholm $P$, Bülow $K$. Response to double burst appears before response to train-of-four stimulation during recovery from non-depolarizing neuromuscular blockade. Acta Anaesthesiol Scand, in press. 